why, during the Krakatao outburst, the antipodes was more favourably situated for an eruption than the other volcanic regions of the earth. A similar tendency during former eruptions has not been recorded, and we must wait until another great outburst enables us to decide whether it is of any importance.

The coloured drawings, twenty-five in number, are all by Mr. Schreuders, who accompanied Mr. Verbeek in October 1883 , and give a faithful picture of the devastated regions as they appeared two months after the eruption. The most striking picture is that of the stupendous wall, 832 metres high, which was laid bare by the destruction of the northern part of the peak. No one who has gazed upon this grandest of nature's ruins can forget its solemn desolation.

The careful typographical execution of the work reflects great credit on the Director of the Government Printing Office at Batavia. We can heartily congratulate the learned author on the successful completion of his most valuable and exhaustive work, interesting alike to the scientific and general reader.

\section{ON THE COLOUR-SENSE}

THERE is an interesting paper in the Nineteenth Century ${ }^{1}$ for February last in which the colournomenclature in the Homeric poems and that of the modern Hindústání language are compared with modern English usage. The writer traverses to a great extent Mr. Gladstone's suggestion ${ }^{2}$ that the ancient Greeks were deficient in colour-sense (i.e. compared with modern Englishmen), and propounds the idea that the natives of India have a keen colour-sense.

It will be shown below that the use of colour terms in modern English is not only loose, but even incongruous. Illustrations will be taken from both the papers referred to, with additions from the author's experience in India.

Natural Objects.-Uniformity might surely be expected in the use of colour terms with bright-coloured natural objects. There is, however, no uniformity in their use, even when intended to be real colour designations; and opposite and sometimes unnatural colours are-in a figurative sense-ascribed to a single object.

Thus the colour of fresh blood and the tint arising therefrom in the healthy cheek and also in the blushing cheek (of a fair person) are probably among the most well-marked, definite, natural colours. Yet the blood itself is styled blood-red, gory, crimson, red, scarlet, whilst the healthy cheek is described as carnation, vermeil, red, ruddy, rosy, and pink, and the blushing cheek as scarlet, crimson, red, aflame (perhaps rather a heat than a colour term). These terms, though used as real colour designations, are by no means synonymous, whilst in a figurative sense quite different and even unnatural colours are ascribed. Thus blue blood is used of aristocratic descent, black blood and white or pale blood of descent from dark or fair races.

Again, healthy bile is bright yellow, and a yellowish tinge in the "white" of the eye is often called a bilious colour; yet in the figurative sense black is ascribed to the condition known as melancholy, atrabiliousness, black bile.

The colour of good milk is so characteristic as to give rise to the term milk white, whilst skim-milk or poor milk which has merely a blueish tinge is styled sky-blue.

Again, the parts of the human eye and of a bird's egg styled from their characteristic tint the wite of the eye and the white of an egg, always bear the name of white, although occasionally of a decidedly blueish tinge, stronger than that of skim-milk.

Colour is usually ascribed to the human eye from the

x "Light from the East on the Colour Question," by W. J. Furrell, p. 321 of Nineteenth Century for February, 1885 .

2 "The Colour Sense," by the Right Honourable W. E. Glads!one, M.P., p. 366 of Nineteenth Century for October, 1877 . tint of the iris, probably as being the part most subject to colour-variation-e.g. black, dark, pink, brown, hazel, green, biue, gray, light. Of these, black is loosely applied (e.g. in the phrase black-eyed) in the case of any darkcoloured iris, whilst green and blue are used in the case of a mere tinge of green or blue.

On the other hand the phrase red eyes indicates either redness of the eyes (as from weeping) or a bloodshot state of the "whites," whilst a black eye implies only a dark-coloured bruise of the skin near the eye; green in the eye is a figurative expression implying freshness or ignorance, and green-eyed is a condition ascribed to jealousy.

The colour of sea-water varies from greenish (aquamarine) to a deep blue (ultramarine); but a wide range of colour-names is applied to various seas-e.g. the Black Sea, Red Sea, Yellow Sea, White Sea, and this in many languages.

The colour of river-water varies from turbid yellow to blueish and colourless; but in this case there is an equally wide range of colour-name-e.g. Blackadder R., Blackwater R., Red R., Orange R., Green R., Blue R., Blue Nile, Grey R., White R., White Nile, Whiteadder R.

Human Colouring.-Colour-terms, applied to races of men, or to the complexion or hair, are loosely used to cover a wide range of colour. Thus black, dark, dusky, swarthy, and nigger (lit. black), are applied to any merely dark skins; red and coppery to the whole of the North American (so-called) Indians; white and pale to any fair skin. The terms dark and fair (shade- rather than colournames) are loosely applied both to the complexion and to personal description. Thus any complexion darker than the average in a fair race, or fairer than the average in a dark race, is called dark or fair respectively; the two terms being merely relative in this usage.

Also among a fair race, a person with dark eyes and dark hair is called dark, and one with light eyes and fair hair is called fair, without reference to complexion. Again, the terms red, carroty, fiery are often applied to hair which has merely a reddish tinge.

Among races of different complexion in the same country curious figurative usages of the racial colourterms arise. Thus nigger (lit. black), black, dark, redskin are sometimes used by a (ruling) fair race to denote inferiority, and this usage is sometimes adopted even by the (ruled) dark race-e.g. occasionally by both negroes and natives of India. There is a curious restricted use of the phrase gorá $\log$ (lit. fair people) in India to denote the British soldiery, but not the higher classes of English.

Animal Colours.--Colour terms applied to animals have sometimes a technical meaning quite different to the fundamental colour. Thus bay and strawberry, as applied to horses, are very different colours from those of the bay-leaf and strawberry; thus also the Hindústání term $s a b z$, usually meaning green, denotes gray when applied to animals. Again, red is applied to animals-e.g. cows, deer, foxes, squirrels, \&c., whose coats are any sort of reddish-brown. A similar usage occurs in the Homeric

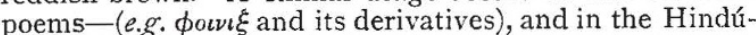
stání word lál (lit. ruby).

Colour-terms are sometimes applied to animals, plants, \&c., even when only slightly affected with the named colour, to indicate a particular variety of the object in question. Thus a blue pigeon, fox, or rabbit, is only slaty blue; a white elephant is only spotted with white pink patches; a blood orange may be only speckled with blood-markings; a black lion and black leopard are only dark with black markings. Colours differing from nature are also ascribed to animals on signboards-e.g. black, red, blue, white lion; blue bear, \&c. ; thus also green man; also (in cookery) a green goose.

Artificial Objects.-Among artificial objects, even of strongly-marked hue, colour-terms are often strangely mis- 
applied (sometimes apparently by contrast with the characteristic colour). Thus all wines which are not of some red tint are loosely styled white wines, though their real colours are various shades of yellow, golden, and orange. Again, light-coloured hats, usually light gray, drab, or brown, are often styled white hats, probably in contrast with the black chimney-pot hat so common in England. The colour-term green with the figurative sense of "fresh," is applied to unseasoned timber and to freshly-quarried stone.

Metals.-Whilst some few metals have a sufficiently striking colour to give rise to a special colour-name-e.g., coppery, bronze, brazen, golden, aureine, steel-blue, leaden, iron-grey, argent, silvery, the most of them have a general similarity of tint, and are loosely called white (probably in contrast to the coloured metals), whilst a mere tinge of blue in some of them leads to their being called blue (e.g., lead, zinc, steel).

Curious applications occur in trade names: thus, white metal is used of any cheap alloy resembling silver in appearance; white brass is a whitish alloy of copper and zinc; gray iron and white iron are cast iron whose fracture is grey or white; whilst white lead, zinc white, white arsenic are the white oxides of the metals in question; red lead is the red oxide of lead, and black lead is really plumbago (which resembles lead only in its property of marking paper); white, yellow, orange, and red, when applied to gold, denote alloys of gold in which the golden colour is modified slightly in the directions indicated; red-short is an epithet descriptive of malleable metals which are brittle when hot.

Blue and Black.-There is a curious confusion between dark blue and black in both English and Hindústání. Thus, in English there are blue-black, invisible blue (both used of a very deep blue almost black), black and blue (applied to a bruise), black as ink and inky black (although most inks are nowadays blueish) often applied to rainclouds (nimbus) and to the deep indigo blue of the deep sea, quite like the Hindústání phrase kálá pání (lit. black water) used of the sea. Dark blue cloth is by some (even by ladies) habitually called black; the writer has also known blackberries miscalled blaeberries (by a Scotchwoman), although blae is literally blue ; this is quite like the Hindústáni word kálá, which is used for both black and dark blue, especially in cloth. This confusion is curious in English, wherein the terms jet-black, jetty, coal-black, exist for a true black. In the melody, "The Coal-black Rose," the colour is attributed really to a person of the name of Rose.

Physical States.-Colour-terms are applied to physical states, sometimes in an exaggerated sense (the name of a bright colour being ascribed to any faint tint of the same), and sometimes in a special and almost inexplicable sense.

Thus we speak of the black death, as black as death, black looks, looking as black as thunder, scarlet fever, yellow fever, jaundice, turning green with sickness, being beaten black and blue, blue with cold, a fit of blue devils, pale or white with illness or with loss of blood.

Mental, E'c., States. - The connection of colour terms with mental and moral emotions, conditions, and actions, is curious and often inexplicable.

Thus black is associated with the idea of evil-e.g. the blackest of lies, black as sin, blackened with crime, as black as the devil; and also with degradation in both English and Hindústání-e.g. to blacken one's face (Hind. munh kálá karná) implies disgrace in both languages. Again black, purple, crimson, red, scarlet, pink, livid, pallid, and scarlet are also ascribed to shame, in both cases doubtless from their effect on the hue of the cheek. Further crimson, red, and scarlet are associated with crime (probably from their connection with blood), and also with sin generally-e.g. red-handed, sins as scarlet, the scarlet woman, \&c. Next black, yellow, and blue are all used of depression of spirits-e.g. in the words melancholy, atrabilious, jaundiced, a fit of the blues. Again, green and verdant are used of the freshness of youth and of the state of a novice, and in this use both these colour-terms are oddly attributed to the eye ; whilst green is also applied to (unusual) freshness in old age. The terms green, blue (e.g. a blue funk), pale, pallid, livid, ashy, gray, and white are all used as descriptive of fear; similarly the words $\chi \lambda$ wops (commonly translated green) in Homer and zard (commonly translated yellow) in Hindústání are used of fear.

Again, blue is sometimes associated with religious feeling, and also with literary or scientific pursuits among women, e.g., blue-stocking. Lastly, white is associated with the idea of good (perhaps in contrast to black, which goes with evil), e.g. white lie (i.e. a slight or venial lie), to be whitewashed (i.e. freed from debt), and extreme whiteness is associated with purity (probably from the pure whiteness of snow) e,g. sins shall be as white as snow, white-robed angels, \&c.

Summary.-With such a looseness in the use of colourterms in modern English and Hindústání as exemplified above, it seems (to the writer) that it is hardly possible to draw inferences as to the strength of the colour-sense in either the past or present from the (supposed) correct or incorrect application of colour-terms by other nations. Paucity of colour-terms is probably fair evidence of a poor colour-sense, whilst an abundance of the same is probably good evidence of a fine colour-sense. Viewed by this test, the colour-sense evidenced in the Homeric poems is certainly poor, and that of the natives of India is also poor compared with that of modern western nations ; as to the latter, it may be said that a great development of colour-sense is now going on, and much more rapidly than in the past, judging from the frequent additions to the stock of dyes and pigments of late years, especially since the discovery of aniline and its derivatives.

Natives of India.-The author of "Light from the East on the Colour Question" considers that there is a "highly-developed colour-sense among the natives of India," and adduces the Indian coloured textile fabrics and works of art as evidence of this. This does not agree with the present writer's experience from a residence extending over twenty-three years in North India. The textile fabrics have certainly a good blending of colours; the cloth dyes and colours laid on pottery and other art-productions are also often beautiful. But the cloth-workers, dyers, potters, and other artisans in colours, and the educated classes, are the few among whom the colour-sense is well developed, and they are few among the $250,000,000$ of India. The colour-terminology of Hindústání is poor, especially out of the classes abovenamed. Moreover, in the writer's experience the eyesight of the uneducated masses in India is defective in every way. They have great difficulty in threading a needle, in reading small type or small MS., also in reading at all except in a strong light, in discriminating colours, and (strangest of all) in making anything out of a picture, engraving, or photograph. This last defect is at first sight most surprising to an Englishman: it would seem as if a certain "picture-education" were necessary to develop a " picture-sense." A villager in India, or a quite uneducated servant, will sometimes examine a picture sideways, or even upside down, and will hazard the most incongruous ideas as to the subject, even when it is that of an object quite familiar to him.

\section{Allan Cunningham}

\section{ENSILAGE}

WE have observed with satisfaction, if we may be allowed to say so, the increasing attention which is being devoted to the subject of ensilage in this country, not only in view of the importance of this method of 